\title{
O ESTÁGIO SUPERVISIONADO COMO EXPERIÊNCIA DOCENTE: DISCUSSÕES SOBRE O PROCESSO DE ENSINO-APRENDIZAGEM
}

\author{
José Robbyslandyo da Silva Santos
}

\begin{abstract}
RESUMO
Este artigo tem sua gênese nas experiências vivenciadas na disciplina de Estágio Supervisionado IV; estágio este desenvolvido na Escola Estadual Prof. Crispim Coelho na cidade de Cajazeiras-PB. Sob a supervisão do professor titular da turma (professor-supervisor) realizei meu estágio na turma do $2^{\circ}$ ano do Ensino Médio Regular, no turno da noite; essa turma era relativamente pequena com apenas 16 (dezesseis) alunos/as. Para esse estágio nos foi proposto o "desafio" da inserção da Física Moderna e Contemporânea na sala de aula. Apresentei os conteúdos de forma expositiva utilizando o data-show procurando dar enfatizando na construção históricas da Teoria da Radiação de Corpo Negro mostrando as consequências que essa teoria trouxe para a física clássica e para o entendimento da natureza. Para o desenvolvimento do estágio, a partir do conteúdo programado pelo professor-supervisor foi utilizado o Livro-Didático dos/as alunos/as como referencial bibliográfico e também trechos do livro "Quanta Física" que foram disponibilizados a todos/as os/as alunos/as; o estágio foi desenvolvido durante 6 (seis) semanas contando sempre com a participação e contribuição do professor-supervisor. Algumas dificuldades foram encontradas durante o estágio, como por exemplo, dificuldades de leitura e interpretação de texto, dificuldades com cálculos matemáticos e no entendimento das teorias físicas; apesar das dificuldades os/as alunos/as mostraram interesse e presteza e houve uma significativa mudança de atitude e comportamento na sala de aula. O objetivo do presente artigo é discutir a importância do ensino da Física Moderna e Contemporânea no Ensino Médio a partir de um relato de experiência e diante dos resultados podemos concluir que a Física Moderna e Contemporânea poderá mobilizar competências e habilidades construídas nas aulas de Física, uma vez que, o conteúdo a ser ensinado e, posteriormente avaliado, faz parte do cotidiano desses sujeitos, como também das suas construções histórico-sociais.
\end{abstract}

Palavras-chave: Ensino-aprendizagem, Física Moderna e Contemporânea, modelos.

\section{THE SUPERVISED INTERNSHIP AS A TEACHING EXPERIENCE: DISCUSSIONS ON THE PROCESS OF TEACHING-LEARNING}

\begin{abstract}
This paper has its genesis in the experiences lived in the course of Supervised Internship IV; this stage developed in the State School Prof. Crispim Coelho in the city of Cajazeiras-PB. Under the supervision of the holder of the class teacher (teacher-supervisor) conducted my internship class in the 2nd year of High School, the night shift; this group was relatively small with only 16 (sixteen) students. For this stage has been proposed the "challenge" the insertion of Modern and Contemporary Physics in the classroom. I presented the contents of expository using data-show looking to emphasizing the historical construction of blackbody radiation theory showing the consequences that this theory brought to classical physics and the understanding of nature. For the development stage, from the content programmed by the
\end{abstract}


teacher-supervisor was used Textbook of the students as bibliographic references and also excerpts from the book "Quanta Física" that were made available to all students; the stage was developed during 6 (six) weeks always with the participation and contribution of the teachersupervisor. Some difficulties were encountered during the stage, such as difficulty reading and reading comprehension, difficulties with mathematical calculations and understanding of physical theories; despite the difficulties students showed interest and promptness and there was a significant change of attitude and behavior in the classroom. The purpose of this paper is to discuss the importance of teaching Modern and Contemporary Physics in high school from an experience report and on the results we can conclude that the Modern and Contemporary Physics can mobilize skills and abilities built in Physics classes a since the content to be taught and subsequently evaluated, is part of the daily life of these subjects, as well as its historicalsocial constructions.

Keywords: teaching-learning, Modern and Contemporary Physics, models.

\section{INTRODUÇÃO}

Este artigo relata algumas experiências vividas durante o estágio realizado na Escola Estadual de Ensino Fundamental e Médio Prof. Crispim Coelho, situada na cidade de Cajazeiras-PB, escola pública e tem como modalidades de ensino: Ensino Fundamental, Ensino Médio Regular e Ensino Médio para de Jovens e Adultos. A escola funciona no turno da manhã, tarde e noite; seus/as alunos/as em sua maioria são residentes da zona urbana da cidade, com alguns/mas alunos/as residentes no campo.

O Estágio Supervisionado é um Componente Curricular Obrigatório de muita importância para formação de futuros/as professores/as dando-lhes a oportunidade de colocar em prática as concepções teóricas que foram estudadas durante o curso. O Estágio do Curso de Física-Licenciatura do Centro de Formação de Professores (CFP) pressupõe atividades pedagógicas efetivadas em um ambiente institucional de trabalho, reconhecido por um sistema de ensino, que se concretiza na relação educacional, estabelecida entre um/a professor/a supervisor/a e um/a aluno/a estagiário/a e tem como objetivo, proporcionar ao/a estagiário/a uma reflexão contextualizada, conferindo-lhe condições para que se forme como autor/a de sua prática, por meio da vivência institucional sistemática, intencional, norteada pelo projeto pedagógico do curso de Física-Licenciatura da Universidade Federal de Campina Grande/CFP

O professor-supervisor era contratado na escola e não possuía formação em Física; a não formação em Física do professor-supervisor influenciava em demasiado as aulas no que se refere ao conteúdo substancial da Física; os conceitos muitas vezes não 
eram apresentados de forma correta prejudicando os/as alunos/as na aprendizagem dos conceitos da Física, conceitos esses de extrema importância para o entendimento da natureza; na tentativa de contribuir para a superação desses problemas nos reuníamos constantemente com o professor-supervisor e com o professor-coordenador do subprojeto buscando majorar a qualidade substancial dos conceitos físicos ensinados. A metodologia utilizada pelo professor-supervisor era basicamente tradicional, onde a mera memorização e a repetição eram exigidas dos/as alunos/as contribuindo para a ineficiência do ensino e na falta de participação ativa dos/as alunos/as na sala de aula.

\section{Ensino Tradicional: algumas reflexões}

É quase que unanimidade a rejeição do Ensino Tradicional, pelos/as professores/as e, principalmente, pelos/as futuros/as professores/as que estudam durante a graduação novas práticas pedagógicas de cunho construtivista que conduzem ao abandono dessa metodologia de ensino e fazem com que esses/as alunos/as critiquem ferozmente o modo tradicional de ensinar.

Na concepção dessa forma de ensino, o/a professor/a é detentor do saber e, para isso, ele/ela deve dominar todo o conteúdo a ser ensinado, sem preocupar-se com o que os/as alunos/as sabem, pois esses/as devem memorizar o que está sendo "ensinado" para que seja reproduzido na prova, como produto final, todas as informações/conhecimentos prontos e acabados igualmente ao que eles/elas ouviram.

Sendo assim, surgem alguns questionamentos que nos inquietam enquanto críticos dessa forma de educação: Será que esses/as mesmos/as professores/as realmente têm fundamentação teórica para realizar tais críticas? Eles/as sabem realmente o que é Ensino Tradicional? Quais as vantagens de um ensino construtivista para o processo do ensino-aprendizagem?

A palavra ensinar pode ser definida de acordo com a visão de mundo do/a professor/a. Alguns/mas professores/as definem ensinar como: "transmitir conhecimento" e outros/as definem ensinar como um processo onde se constrói e/ou reconstrói conhecimento e nesse sentido Freire (1996) nos chama atenção quando afirma que ensinar não é transferir conhecimento, ensinar é criar possibilidades para a sua própria produção ou para sua construção.

RPI Revista de Pesquisa Interdisciplinar, Cajazeiras, v. 1, Ed. Especial, 532 - 542, set/dez. de 2016. 
Uma educação para o século XXI exige muito mais que o abandono da prática da transmissão de conhecimento por parte dos/as professores/as; exige uma prática educativa na qual o construir e compartilhar conhecimentos seja um movimento contínuo no cotidiano do processo de ensino-aprendizagem. A aprendizagem, é entendida, dessa forma, como processo e está intimamente interligada com o ensino, processo esse de uma fantástica complexidade.

De acordo com as novas tendências contemporâneas o processo de ensinoaprendizagem está centrado na construção e/ou reconstrução de conhecimentos relacionados com a realidade do/a aluno/a, ou seja, conhecimentos que fazem parte do seu cotidiano. Nesse processo, o/a professor/a é o/a mediador/a; e mediar é intervir para promover mudanças cognitivas de forma comunicativa, bem como colaborando em seu papel na sala de aula.

Dessa forma, a aprendizagem, enquanto parte crucial do processo, torna-se significativa à medida que o novo conteúdo é incorporado às estruturas de conhecimento do/a aluno/a e adquire significado para ele/a a partir da relação com seu conhecimento prévio e ela se torna mecânica ou repetitiva, uma vez que se produziu menos essa incorporação e atribuição de significado, e o novo conteúdo passa a ser armazenado isoladamente ou por meio de associações arbitrárias na estrutura cognitiva que comumente chamamos "decorar" os conteúdos.

\section{As contribuições da Física Moderna e Contemporânea}

O conteúdo da Física Moderna e Contemporânea faz parte da sociedade atual; também conhecida como sociedade da informação e do conhecimento. Privar os/as alunos/as de terem contato com esses conhecimentos causará sérios problemas na formação básica destes/as, pois a Física Moderna e Contemporânea contribui na compreensão do funcionamento de certas tecnologias, próprias do cotidiano desses jovens, como por exemplo, os smartphones, notebooks, aparelhos de televisão, entre outros.

Essas tecnologias estão em constantes avanços e, esses avanços, não são abordados na sala de aula, criando um abismo entre o conteúdo ensinado e o cotidiano do/a aluno/a. Valadares e Moreira (1998, p. 121) afirmam que:

RPI Revista de Pesquisa Interdisciplinar, Cajazeiras, v. 1, Ed. Especial, 532 - 542, set/dez. de 2016. 
É imprescindível que o estudante do segundo grau conheça os fundamentos da tecnologia atual, já que ela atua diretamente em sua vida e certamente definirá o seu futuro profissional. Daí a importância de se introduzir conceitos básicos de Física Moderna e, em especial, de se fazer uma ponte entre a física da sala de aula e a física do cotidiano.

O conteúdo da Física abordado na sala de aula se resumem à Física desenvolvida até meados do século XIX. Todos os avanços alcançados depois desse século, ou seja, os conhecimentos físicos construídos desde o século $\mathrm{XX}$, bem como as tecnologias informadas por esses conhecimentos científicos, até a atualidade são simplesmente deixados de lado, como se eles não existissem. Esses conteúdos muitas vezes estão lá expressos nos Livros-Didáticos que são adotados pelos/as professores/as no processo de ensino-aprendizagem.

Muitos são os motivos para o abandono da Física Moderna e Contemporânea e um deles, e talvez o principal, seja as dificuldades intrínsecas ao ensino desse tema. Alguns/mas professore/as não saem devidamente preparados/as da formação inicial para ensinar conteúdos, tais como a Teoria da Radiação de Corpo Negro, Efeito Fotoelétrico, o Efeito Compton, Átomo de Bohr, dentre outros. Entendemos que não basta apenas mudar os currículos escolares sem uma formação adequada para os/as professores/as, eles/as são os/as mediadores/as do processo de ensino-aprendizagem e isso exige o domínio do conhecimento a ser compartilhado.

Os/As professores/as preferem ensinar apenas conteúdo da Física Clássica talvez porque tenham mais segurança com relação ao que sabem do tema; eles/as se sentem mais confortáveis e por isso acreditam que são mais eficientes ensinando o que dominam.

Diante desse quadro, de uma quase total ausência do Ensino da Física Moderna e Contemporânea na Educação Básica o professor-coordenador da disciplina de Estágio Supervisionado IV propôs o "desafio" da inserção da Física Moderna e Contemporânea no conteúdo programado pelo professor-supervisor da escola; a partir dos conteúdos disponibilizados pelo professor-supervisor durante o desenvolvimento do estágio pretendi que o final das atividades os/as alunos/as sejam capazes de: Saber que a Física é construída a partir de modelos; Entender a ciência como cultura; Saber a 
definição de corpo negro; Saber que existe interação da radiação com a matéria; Conhecer os conceitos científicos, as grandezas físicas e os fenômenos relacionados à Termodinâmica; Diferenciar os conceitos de temperatura e calor; Compreender o funcionamento de um termômetro; Realizar conversões de valores entre as escalas termométricas mais utilizadas; Identificar como ocorrem as trocas de calor

\section{Metodologia}

O Estágio deve propiciar ao/a futuro/a professor/a o conhecimento de seu campo de trabalho e o relacionamento teórico-prático da realidade com os conhecimentos adquiridos nas diversas disciplinas. O período de Estágio se apresenta como um espaço do "como se ensina a ensinar" e "como se aprende a aprender". Assim, identifico o estágio como à oportunidade do/a aluno-professor vivenciar os conhecimentos e as atividades adquiridas durante o curso.

O estágio foi realizado na forma de Regência na turma do $2^{\circ}$ ano do Ensino Médio Regular, turno da noite; a turma é relativamente pequena contando apenas com 16 (dezesseis) alunos/as, residentes na zona urbana de Cajazeiras e em sua grande maioria jovens e adultos inseridos no mundo trabalho. Assumi a turma para poder desenvolver minhas atividades a partir do planejamento do professor-supervisor que havia programado para o período os conteúdos da Termodinâmica: Calor; Escalas termométricas; Calor específico; Capacidade térmica e Quantidade de calor. De acordo com a proposta do Estágio Supervisionado IV, os conteúdos da Física Moderna e Contemporânea estarão presentes no programa proposto. $\mathrm{Na}$ abordagem do conteúdo temperatura foi introduzido o problema da Radiação do Corpo Negro que é definido como corpo que emite um espectro de radiação universal que depende apenas de sua temperatura. Este tipo de corpo absorve toda a radiação que incide sobre ele.

O primeiro contato foi reservado para observação da turma com o objetivo de conhecer a metodologia do professor e os/as alunos/as. A aula de Física tem início às 19:30 e término às 20:40; a carga-horária é menor a noite devido o curto tempo de aulas, apenas 4 (quatro) horas. Pude perceber que a turma é bastante tranquila, apesar de alguns/mas alunos/as conversarem durante a aula.

RPI Revista de Pesquisa Interdisciplinar, Cajazeiras, v. 1, Ed. Especial, 532 - 542, set/dez. de 2016. 
Durante 6 (seis) semanas assumi a turma nas aulas de Físicas e acordo com o horário da escola, nossas aulas foram realizadas na quinta-feira; no turno da noite são apenas 2 (duas) aulas semanais de Física para o $2^{\circ}$ ano do Ensino Médio Regular; apresentei os conteúdos de forma expositiva utilizando data-show, que é uma ferramenta muito interessante que possibilita o uso de imagens e vídeos tornando a aula muito mais atrativa. As aulas tiveram como ênfase a construção históricas da Teoria da Radiação de Corpo Negro e mostrando as consequências que essa teoria trouxe para a física clássica e para o entendimento da natureza.

\section{Conclusões}

Muitas são as razões para esse abandono da chamada Física Moderna e Contemporânea nas aulas de Física. Um motivo bem argumentado pelos/as professores/as é a falta desses conteúdos em provas externas, como por exemplo, o ENEM (Exame Nacional do Ensino Médio) que hoje é via de acesso ao Ensino Superior brasileiro. Passar no ENEM não pode ser objetivo da escola e mesmo sendo o objetivo principal da escola de hoje ela não vem atingindo seu objetivo. É preciso mudar a escola atual, antes mesmo de ensinar os conteúdos da Física é preciso ensinar aos/as alunos/as o que se faz na escola, para que serve a escola. A escola hoje tem como objetivo final a aprovação no ENEM, ela obriga o/a professor/a seguir esse objetivo, fazendo que aulas de resolução de vestibulares seja uma prática comum; praticamente a escola obriga que o/a professor/a seja tradicional

Segundo alguns/mas professores/as, não há razão para se cobrar tais conhecimentos da Física no ENEM, pois os mesmos exigem a utilização de cálculos avançados que estão longe da compreensão dos/as alunos/as da Educação Básica; é certo que a matemática que descreve os modelos da Física Moderna e Contemporânea são avançados, mas é possível uma abordagem centrada na formulação histórico-social da Física Moderna e Contemporânea, abordagem que mostre as mudanças conceituais que surgiram e suas consequências para um novo entendimento da natureza . Por isso, os currículos da Física e de Ciências precisam de mudanças e as pesquisas em Ensino de Física vem evidenciando essa necessidade e de acordo com Ostermann e Moreira (2000, p. 43):

RPI Revista de Pesquisa Interdisciplinar, Cajazeiras, v. 1, Ed. Especial, 532 - 542, set/dez. de 2016. 
Parece que há muitas justificativas em favor da atualização curricular e até uma bibliografia que apresenta (não tão aridamente como a literatura especializada) temas modernos. Entretanto, colocar todas estas reflexões na prática da sala de aula é ainda um desafio. Outra questão desafiadora é a escolha de quais tópicos de FMC deveriam ser ensinados nas escolas ou, o que dá no mesmo, de quais temas de FMC deveriam ser objeto de especial atenção na formação de professores de Física com vistas a uma adequada transposição didática para o ensino médio.

É nesse contexto que consideramos de extrema importância o ensino da Física Moderna e Contemporânea na Educação Básica, pois os conteúdos relacionados com esse tema fazem parte do cotidiano dos/as alunos/as e, dessa forma, poderão contribuir para os/as mesmos/as compreenderem o funcionamento de smarthphones, de notebooks, de lazers, aparelhos de televisão de LED, dentre outros. A Física Moderna e Contemporânea poderá mobilizar nestes sujeitos competências e habilidades construídas nas aulas de Física, uma vez que, o conteúdo a ser ensinado e, posteriormente avaliado, faz parte do cotidiano desses sujeitos, como também das suas construções históricosociais

O período de estágio é de extrema importância para a formação profissional docente, esse período possibilita viver e sentir na prática as várias dificuldades do/a professor/a: planejamento, transposição didática, entre outros fatores que estão presentes na vida do/a professor/a e que influenciam sua prática pedagógica. Nesse período percebi que a escola precisa de mudanças. É possível mudar a escola e os/as futuros/as professores/as tem a obrigação de acreditar numa escola de qualidade para todos/as. Canário (2006, p. 92) afirma que:

Reinventar a escola pressupõe uma atitude crítica e de profunda insatisfação com a escola atual, mas também a convicção de que é possível e desejável criar uma 'outra' escola, radical e qualitativamente distinta da de hoje.

Apesar de dificuldades na leitura e interpretação dos textos, dificuldades nos cálculos matemáticos, pouca participação dos/as alunos/as nas aulas que já chegam na escola depois de uma dura jornada de trabalho; todas essas dificuldades encontradas durante o estágio foram sendo vencidas com persistência procurando mobilizar os/as alunos/as a participarem mais ativamente nas aulas e pelos relatos do professor- 
supervisor essa persistência trouxe bons reflexos em sala de aula com diminuição no número de faltas, menos indisciplina e participação mais ativa dos/as alunos/as nas aulas de Física.

Portanto, podemos concluir que a Física Moderna e Contemporânea pode mobilizar competências e habilidades construídas nas aulas de Física, uma vez que, o conteúdo a ser ensinado e, posteriormente avaliado, faz parte do cotidiano desses sujeitos, como também das suas construções histórico-sociais

\section{REFERÊNCIAS}

CANÁRIO, Rui. A escola tem futuro? Das promessas às incertezas. Porto Alegre/RS: Artmed, 2006, p. 160.

FREIRE, P. Pedagogia da autonomia: saberes necessários para a prática educativa. 25. ed. São Paulo/SP: Paz e Terra S/A, 1996, p. 54.

OSTERMANN, F.; MOREIRA, M. A. Uma revisão bibliográfica sobre a área de pesquisa "Física Moderna e Contemporânea no Ensino Médio". Investigações em Ensino de Ciências. [s. 1.]: v. 5, n. 1, p. 23-48, 2000.

VALADARES, E. C.; MOREIRA, A. M. Ensinando Física Moderna no segundo grau: Efeito Fotoelétrico, Laser e emissão de Corpo Negro. Caderno Catarinense de Ensino de Física. [s. 1.]: v. 15, n. 2, p. 121-135, ago. 1998. 